\title{
Flecainide compared with a combination of digoxin and disopyramide for acute atrial arrhythmias after cardiopulmonary bypass
}

\author{
THOMAS P GAVAGHAN, ANNE M KEOGH, RAYMOND P KELLY, \\ TERENCE J CAMPBELL, CHARLES THORBURN, JOHN J MORGAN
}

From the Cardiovascular Unit, St Vincent's Hospital, Sydney, Australia

SUMMARY Fifty six adult patients were randomised to treatment with flecainide (group $1, \mathrm{n}=29$ ) or a combination of digoxin and disopyramide (group $2, n=27$ ) for acute atrial fibrillation and flutter after cardiac surgery. Intravenous flecainide was given as a $2 \mathrm{mg} / \mathrm{kg}$ bolus over 20 minutes followed by an infusion $(0.2 \mathrm{mg} / \mathrm{kg}$ per hour) for 12 hours. Group 2 were given digoxin $(0.75 \mathrm{mg})$ intravenously followed two hours later by an intravenous bolus of disopyramide $(2 \mathrm{mg} / \mathrm{kg})$ and an infusion $(0.4 \mathrm{mg} / \mathrm{kg}$ per hour) for 10 hours. Within 12 hours sinus rhythm was restored in $86 \%$ of the group 1 ( 25 patients) and $89 \%$ of the group 2 (24 patients). The median time to reversion was significantly shorter in group 1 (80 minutes, range 30-180 minutes) than group 2 (220 minutes, range 138-523 minutes). None of the patients in group 1 and four of the patients in group 2 had transient relapses into atrial fibrillation during the 12 hours of intravenous treatment. There were five late relapses in group 1 and seven in group 2 during subsequent oral treatment. Two group 1 patients and two group 2 patients showed adverse drug effects. Intractable ventricular arrhythmias occurred after five days of oral treatment in one patient (group 1) who had poor left ventricular function, hepatic impairment, and toxic concentrations of drugs at the time of death.

Flecainide was as effective as the combination of digoxin and disopyramide and it acted significantly faster and was associated with fewer relapses. Monitoring of blood concentrations of flecainide is essential in patients with poor left ventricular function and hepatic impairment.

The early postoperative course after open heart surgery is complicated by supraventricular arrhythmias (usually atrial fibrillation or flutter) in 15$90 \%$ of patients. ${ }^{1-3}$ Although reversion to sinus rhythm may occur promptly without treatment, an appreciable proportion of patients will have persistent arrhythmias associated with a rapid ventricular rate, causing distress, impaired myocardial performance, and symptomatic haemodynamic deterioration.

An earlier study at our hospital showed that intravenous sotalol was as effective as a combination of digoxin and disopyramide in restoring sinus rhythm and that it acted significantly faster. ${ }^{4}$ The frequent occurrence of hypotension during the intravenous administration of sotalol and the

Requests for reprints to Dr Thomas P Gavaghan, Cardiovascular Unit, St Vincent's Hospital, Victoria Street, Darlinghurst 2010, Sydney, Australia.

Accepted for publication 27 July 1988 relatively common anticholinergic side effects of disopyramide prompted further investigation of alternative treatment regimens.

In several recent studies flecainide acetate, a class 1c antiarrhythmic drug, was effective in the treatment of spontaneous and inducible supraventricular arrhythmias. ${ }^{5-7}$ In the present study we compared the efficacy and side effects of flecainide given alone with those of a combination of digoxin and disopyramide in patients with acute atrial fibrillation or atrial flutter after cardiac surgery.

\section{Patients and methods}

We studied patients who had heart operations from December 1985 to August 1986 and in whom atrial arrhythmias with a ventricular rate $>110$ beats/min developed after operation. Criteria for exclusion were a history of glaucoma, urinary retention, severe renal impairment (serum creatinine $>0.24 \mathrm{mmol} / \mathrm{l}$ ), 
preoperative atrial arrhythmia or atrioventricular block (second or third degree), bifascicular block, left ventricular ejection fraction $<30 \%$, and the administration of any antiarrhythmic drug (including $\beta$ blockers and digitalis) in the preceding 48 hours.

This was an open parallel group study. If the arrhythmia was present for at least 15 minutes eligible patients were randomly assigned, to one of two groups. The patients in group 1 were given flecainide acetate (Tambocor, Riker Laboratories) $(2 \mathrm{mg} / \mathrm{kg}$ intravenously over 20 minutes followed by a continuous infusion (in $5 \%$ dextrose) of $0.2 \mathrm{mg} / \mathrm{kg}$ every hour for 12 hours). Those in group 2 were given an intravenous bolus of digoxin $(0.75 \mathrm{mg})$. If sinus rhythm was restored within two hours intravenous digoxin (0.25 mg twice daily) was continued. If the arrhythmia persisted for more than two hours patients in group 2 were given disopyramide $2 \mathrm{mg} / \mathrm{kg}$ intravenously (maximum $150 \mathrm{mg}$ ) over 10 minutes followed by an infusion (in 5\% dextrose) of 0.4 $\mathrm{mg} / \mathrm{kg}$ every hour for 10 hours.

The formal comparison of these two treatment regimens ended after the 12 hours of intravenous treatment. The patients in group 1, however, who reverted to sinus rhythm continued to take oral flecainide $100 \mathrm{mg}$ twice a day for the remainder of their hospital stay and for one month after discharge. Similarly, patients who reverted on digoxin alone continued on oral digoxin $0.25 \mathrm{mg} /$ day, and those who reverted on the combination of digoxin and disopyramide continued taking oral digoxin $0.25 \mathrm{mg} /$ day and disopyramide $150 \mathrm{mg}$ four times a day. For both treatment groups, if the arrhythmia persisted after 12 hours of intravenous treatment, further treatment was prescribed by the attending cardiologist.

The electrocardiogram was monitored continuously on a screen and rhythm strips were taken at the time of any rhythm changes. Blood pressure was measured every two minutes for 10 minutes, then every 15 minutes for one hour, and then hourly for 12 hours.

Twelve lead electrocardiograms were recorded during the arrhythmia and within twelve hours of its termination. In those treated with flecainide, blood was collected for measurement of plasma concentrations one hour and 12 hours after start of treatment. Blood for disopyramide assays was not routinely collected in group 2 because this regimen had been shown to produce therapeutic concentrations in similar patients. ${ }^{8}$

\section{STATISTICAL ANALYSIS}

The times to reversion of the arrhythmia are given as the median and interquartile range. The distribution of results in group 1 was highly skewed and so we used the non-parametric Wilcoxon rank sum test to $\sigma$ test for the significance of differences in reversion times. Results were otherwise expressed as (meañ (SD)). We used Student's $t$ test to test for significance of difference in age between the two treatmen 5 . groups. The $\chi^{2}$ test was used to analyse the differen ces in reversion rates and relapse rates between bothp groups.

\section{Results}

Of the 58 eligible patients, 30 were randomly assig ned to group 1 and 28 to group 2. In one of the group 2 patients with atrial flutter $1: 1$ atrioventriculap conduction developed before the start of antios arrhythmic treatment. The patient's rhythm rapidlse degenerated into ventricular fibrillation necessitating urgent cardioversion with the re-establishment of sinus rhythm. This patient was excluded from the analysis.

Another patient from group 1 was treated with intravenous verapamil 30 minutes before the flecai nide bolus and reverted to sinus rhythm after 3.5 hours. This patient was also excluded from the analysis because another antiarrhythmic was useథొ within $\mathbf{4 8}$ hours of the study.

The table shows the clinical details of the remain ing 56 patients. There were no significant differences between the two groups in age, sex ratio, time to onsey of arrhythmia, and ventricular rates before treat $\Phi$ ment. In 25 of the 29 patients in group 1 sinus rhythm was restored during the 12 hours of intravenou? flecainide treatment (figure). Reversion to sinus rhythm occurred 30-180 minutes (median 80 min utes) after the start of the intravenous flecainide

Table Patient details

\begin{tabular}{|c|c|c|}
\hline Data & Group 1 & Group 2 \\
\hline $\begin{array}{l}\text { Number } \\
\text { Male:female } \\
\text { Age (yr) } \\
\text { Time to onset of arrhythmia }{ }^{\star}(\mathrm{hrs}) \\
\text { AF:AFL } \\
\text { Pretreatment ventricular rate }\end{array}$ & $\begin{array}{l}29 \\
24: 5 \\
61 \cdot 9(7 \cdot 3) \\
67 \cdot 6(41 \cdot 4) \\
25: 4\end{array}$ & $\begin{array}{l}27 \\
20: 7 \\
61 \cdot 8(12 \cdot 7 \\
62 \cdot 9(29 \cdot 4 \\
24: 3\end{array}$ \\
\hline & $152(35 \cdot 6)$ & $168(44 \cdot 4)$ \\
\hline $\begin{array}{l}\text { (beats/min) } \\
\text { No taking } \beta \text { blockers preoperatively } \\
\text { No undergoing CABG† } \\
\text { No with preoperative ejection fraction }\end{array}$ & $\begin{array}{l}142(33 \cdot 5) \\
20 \\
26\end{array}$ & $\begin{array}{l}154(28 \cdot 1) \\
21 \\
23\end{array}$ \\
\hline . & 5 & 4 \\
\hline
\end{tabular}

* Measured from the start of cardiopulmonary bypass to the onset arrhythmia.

AF, atrial fibrillation; AFL, atrial flutter.

+ Group 1: two patients had coronary artery bypass grafting (CABG)

plus aortic valve replacement, one had repeat mitral valv

replacement, and one had repair of an atrial septal defect. Group \&

three patients had aortic valve replacement and one had a mitrig

valvotomy.

$\ddagger$ Measured at left ventriculography. 


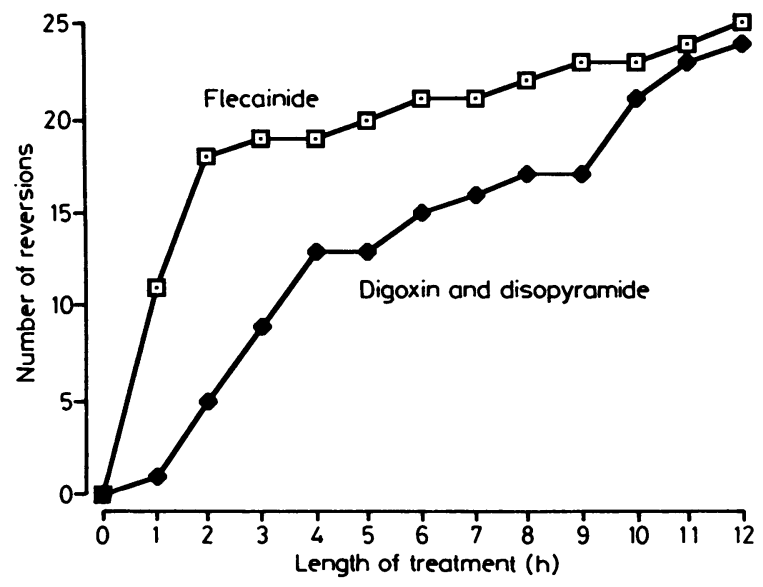

Figure Time course of reversion to sinus rhythm of patients treated with flecainide (group 1) and with a combination of digoxin and disopyramide (group 2).

bolus; in 11 patients the rhythm reverted within an hour. Plasma concentrations of flecainide ranged from 160 to $450 \mathrm{ng} / \mathrm{ml}$ (mean $306 \mathrm{ng} / \mathrm{ml}$ ) at one hour and from 280 to $657 \mathrm{ng} / \mathrm{ml}$ (mean $434 \mathrm{ng} / \mathrm{ml}$ ) at 12 hours. In four patients sinus rhythm did not return during the 12 hours of intravenous flecainide treatment. In two of these, both with atrial fibrillation and flutter, atrial flutter persisted after full intravenous dose of flecainide had been given. One reverted to sinus rhythm six hours after starting oral flecainide and the other returned to sinus rhythm after 82 hours on digoxin and disopyramide after oral flecainide had been stopped. A third patient remained in atrial fibrillation despite the full flecainide infusion, and this arrhythmia persisted for the next five days despite treatment with oral digoxin, flecainide, and, later, quinidine. On day 5 electrical cardioversion to sinus rhythm was successful. The fourth patient received the full dose of intravenous flecainide and remained in atrial fibrillation despite continued oral flecainide (initially at $200 \mathrm{mg} /$ day and later $300 \mathrm{mg}$ / day).

In group 2, 24 out of 27 patients reverted to sinus rhythm within 12 hours (figure). The time to reversion after the bolus of digoxin ranged from 138 to 523 minutes (median 220 minutes). The time to reversion was significantly longer than that in group 1 ( $p<$ 0.001 ). Five patients reverted with digoxin alone at a median of 105 minutes after the bolus and 19 required the combination of digoxin and disopyramide (reverting at a median of 315 minutes after the start of treatment). The three patients in group 2 with persistent arrhythmias at $\mathbf{1 2}$ hours returned to sinus rhythm after 24,29 , and 29 hours respectively of continued oral digoxin and disopyramide.
No patients in group 1 relapsed during the 12 hours of intravenous flecainide; however, five patients relapsed 5-91 hours after the flecainide infusion. In two of these the initial oral flecainide dose had been delayed by nine hours. All five patients reverted to stable sinus rhythm 3-59 hours after relapse, two were continuing to take flecainide 200 $\mathrm{mg} /$ day, one flecainide and digoxin, one flecainide $300 \mathrm{mg} /$ day, and one on digoxin and quinidine.

Two patients who reverted with digoxin alone relapsed 10 minutes and 30 minutes later. They were given intravenous disopyramide and in both of them sinus rhythm returned within 60 minutes. Two patients who responded initially to digoxin and disopyramide relapsed during the disopyramide infusion at two hours and 10 hours. On continued intravenous disopyramide they reverted to sinus rhythm at 10 minutes and five hours respectively. Seven patients who reverted during treatment with digoxin and disopyramide relapsed (after the disopyramide infusion) 6-114 hours after the initial reversion. Three continued on digoxin and disopyramide and reverted to sinus rhythm 10 hours, 13 hours, and 70 hours later. Three were treated with digoxin and quinidine and reverted at two, 15, and 19 hours; and another reverted at 12 hours with digoxin, quinidine, and atrial overdrive pacing for persistent atrial flutter.

\section{SIDE EFFECTS}

Most patients did not show any untoward changes in vital signs after operation. In one patient blood pressure fell significantly from $120 \mathrm{~mm} \mathrm{Hg}$ to $90 \mathrm{~mm}$ $\mathrm{Hg}$ (systolic) immediately after intravenous flecainide. In this case the rhythm was atrial fibrillation with a ventricular rate of $160 / \mathrm{min}$. After the administration of $100 \mathrm{ml}$ of colloid (Haemacel) the blood pressure returned promptly to its previous value without further sequelae.

Another patient, a 68 year old man with congestive heart failure, underwent repeat operation for a leaking mitral valve prosthesis and single coronary artery graft, and atrial fibrillation developed postoperatively. The preoperative left ventricular ejection fraction was 0.34 . Serum concentrations of hepatic transaminases were raised before operation. The arrhythmia persisted despite treatment with flecainide and the dose was increased to $300 \mathrm{mg} /$ day. The QRS complex progressively widened to 0.17 seconds over the next three days without reversion to sinus rhythm. Then treatment with digoxin (0.25 $\mathrm{mg} /$ day) then started. Within 36 hours the patient became dyspnoeic and developed sustained ventricular tachycardia (QRS width 0.24 seconds), which was refractory to repeated cardioversion and several antiarrhythmic agents. Cardiopulmonary resuscitation was unsuccessful and at death the 
plasma concentration of flecainide was $2000 \mathrm{ng} / \mathrm{ml}$ (4.0 $\mu \mathrm{mol} / 1)$.

No adverse effects were noted during the initial 12 hours of treatment in group 2, however, in two patients oral disopyramide ( $600 \mathrm{mg} /$ day) was stopped because of acute urinary retention.

\section{Discussion}

Several recent studies have shown that flecainide acetate is an effective treatment for converting atrial fibrillation and atrioventricular reentrant tachycardias to sinus rhythm. ${ }^{5-7}$ The clinical nature and duration of the arrhythmia in these studies varied. The arrhythmias studied were: tachycardia induced by programmed stimulation, ${ }^{5}$ paroxysmal tachycardia sustained for up to 24 hours, ${ }^{9}$ tachycardia of $<12$ hours' duration, ${ }^{10}$ atrial fibrillation of "recent" onset (within three months), ${ }^{11}$ and atrial fibrillation that had present for up to 140 days. ${ }^{12}$ Despite these different clinical features of the target arrhythmia, flecainide acetate was a very effective treatment, both intravenously and orally, particularly for arrhythmias of recent onset. Reversion of atrial fibrillation $(79-90 \%)$ and atrioventricular re-entrant tachycardias $(89 \%$ ) was successful, but the results of treating recent onset atrial flutter $(20-40 \%)$ were disappointing. ${ }^{6910}$

Few studies have compared the efficacy of flecainide with that of other antiarrhythmic drugs in supraventricular arrhythmias. The study by Borgeat et al, comparing flecainide given intravenously and by mouth with quinidine given by mouth, showed that flecainide was at least as effective as quinidine $(86 \% v 80 \%)$ in terminating atrial fibrillation of less than 10 days' duration. ${ }^{12}$ For suppression of recurrent paroxysmal atrial fibrillation prophylaxis with flecainide in combination with digoxin was more effective than a combination of quinidine and digoxin and a digoxin-only group. ${ }^{13}$

We found that flecainide was as effective as a combination of digoxin and disopyramide in reverting acute onset arrhythmia within 12 hours of start of treatment ( $86 \% v 89 \%$ respectively). The time to reversion to sinus rhythm was significantly shorter in the flecainide group, with $72 \%$ of patients reverting within two hours of treatment compared with only $21 \%$ of patients receiving the standard treatment. The median time to reversion on flecainide was almost one third that of the combination of digoxin and disopyramide (80 min $v 220 \mathrm{~min}, \mathrm{p}<0.001$ ). Furthermore, during the observation period of intravenous and continued oral treatment there were far fewer relapses in the flecainide group.

The choice of flecainide as first line treatment for symptomatic atrial arrhythmias after open heart surgery follows from previous studies at our hospital of the efficacy of disopyramide and sotalol in similai patients. ${ }^{14}$ Unfortunately side effects often limites the continued use of disopyramide and sotalol ande prompted this trial of an alternative treatmen Several studies have evaluated the prophylactic use of low dose $\beta$ blockers in the immediate postoperati period and have shown a significant reduction in the incidence of supraventricular arrhythmias. ${ }^{2314}$ The frequency of arrhythmia in the control groups in these studies $(16-94 \%)$ has, in most cases, beert higher than the $25 \%$ previously found at our hospe ital.

There is an understandable reluctance to treat patients in order to prevent an arrhythmia in a limited number most of whom will respond promptis to specific antiarrhythmic treatment. As a result of the rapid restoration of sinus rhythm with this flecainide treatment, it has now been adopted at our hospital as the usual treatment for postoperativ atrial arrhythmias.

Side effects were equally common in both group however, a lethal arrhythmia developed while one patient was being treated with flecainide $(300 \mathrm{mgt}$ day). The risk in this patient was increased by poog left ventricular function and repeat operation for mitral valve and coronary artery disease. In such cases the incidence of arrhythmogenic effects of antiarrhythmic agents approaches $20 \%$ and may be associated with toxic plasma concentrations. $\frac{\Phi \text { D }}{\Phi}$ Frequent monitoring of plasma concentrations with cautious increases in dose (not more often than everg four days) is important in patients with heart failure, who have a prolonged elimination half life. ${ }^{16}$

We thank the nursing staff and resident doctors of Cameron Wing, the cardiothoracic surgeons and research pharmacist Greg Pearce for their co-operaj tion, assistance, and expert advice in completing the study.

We also thank Riker Laboratories Australia for partial support of this study.

\section{References}

1 Gavaghan TP, Feneley MP, Atrial tachyarrhythmias after cardiac surgery: results of disopyramide therapy. Aust NZ J Med 1985;1 27-32.

2 Oka Y, Frishman W, Becker RN, et al. Clinical phatmacology of the new beta-adrenergic blocking drugs Part 10: beta-adrenoceptor blockade and coronaro artery surgery. Am Heart J 1980;99:255-69.

3 Stephenson LW, MacVaugh H, Tomasello DN

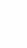


Flecainide compared with a combination of digoxin and disopyramide for atrial arrhythmia Josephson ME. Propranolol for prevention of postoperative cardiac arrhythmias: a randomized study. Ann Thorac Surg 1980;29:113-6.

4 Campbell TJ, Gavaghan TP, Morgan JJ. Intravenous sotalol for the treatment of atrial fibrillation and flutter after cardiopulmonary bypass. Comparison with disopyramide and digoxin in a randomised trial. $\mathrm{Br}$ Heart J 1985;54:86-90.

5 Bexton RS, Hellestrand KJ, Nathan AW, Spurrell RAJ, Camm AJ. A comparison of the antiarrhythmic effects of AV functional reciprocating tachycardia of oral and intravenous flecainide acetate. Eur Heart $J$ 1983;4: 92-102.

6 Nathan AW, Hellestrand KJ, Ward DE, Bexton RS, Camm AJ. Clinical use of intravenous flecainide for acute onset of tachyarrhythmias [Abstract]. Br Heart J 1985;53:87.

7 Creamer JE, Nathan AW, Camm AJ. Successful treatment of atrial tachycardias with flecainide acetate. $\mathrm{Br}$ Heart J 1985;53:164-6.

8 Campbell TJ, Morgan JJ. Treatment of atrial arrhythmias after cardiac surgery with intravenous disopyramide. Aust NZ J Med 1980;10:644-9.

9 Crozier I, Ikram H, Kenealy M, Levy L. Flecainide acetate for conversion of acute supraventricular tachyarrhythmias to sinus rhythm. Am J Cardiol 1987;59:607-9.

10 Hellestrand KJ, Bexton RS, Nathan AW, Camm AJ.
Efficacy of intravenous flecainide acetate for the control of recent onset paroxysmal supraventricular and ventricular tachycardias [Abstract]. Aust NZ J Med 1984;14:4.

11 Goy J-J, Maendly R, Grbic M, Finci L, Sigwart U. Cardioversion with flecainide in patients with atrial fibrillation of recent onset. Eur J Clin Pharmacol 1985;27:737-8.

12 Borgeat A, Goy JJ, Maendly R, Kaufman U, Grbic M, Sigwart U. Flecainide versus quinidine for conversion of atrial fibrillation to sinus rhythm. Am J Cardiol 1986;58:496-8.

13 Steinbeck G, Doliwa R, Bach P. Cardiac glycosides for paroxysmal atrial fibrillation? [Abstract]. Circulation 1986;74 (suppl II):II-100.

14 Daudon P, Corcos T, Gandjbakhch I, Levasseur JP, Cabrol A, Cabrol C. Prevention of atrial fibrillation or flutter by acebutolol after coronary bypass grafting. Am J Cardiol 1986;58:933-6.

15 Roden DM, Woolsley RL. Medical intelligence-drug therapy-flecainide. N Engl J Med 1986;315:36-41.

16 Conard GJ, Ober RE. Metabolism of flecainide. Am J Cardiol 1984;53:41B-51B.

17 Franciosa JA, Wilen $M$, Weeks CE, Tanenbaum $R$, Kvam DC, Miller AM. Pharmacokinetics and hemodynamic effects of flecainide in patients with chronic low output heart failure. J Am Coll Cardiol 1983;1:699-705. 